Farum

Sociológico

\section{Forum Sociológico}

Série II

32 | 2018

Fraturas sociais e educativas: Desafios para a sociologia da educação

\title{
A autoridade docente e os discursos e lógicas atuantes dos professores face à participação dos encarregados de educação no processo educativo
}

Teachers' authority and the discourses and acting logics regarding the participation of parents in the educational process

José Manuel Resende, Luís Gouveia e David Beirante

\section{(2) OpenEdition}

Journals

Edição electrónica

URL: https://journals.openedition.org/sociologico/1898

DOI: 10.4000/sociologico.1898

ISSN: 2182-7427

Editora

CICS.NOVA - Centro Interdisciplinar de Ciências Sociais da Universidade Nova de Lisboa

Edição impressa

Paginação: 7-17

ISSN: 0872-8380

Refêrencia eletrónica

José Manuel Resende, Luís Gouveia e David Beirante, «A autoridade docente e os discursos e lógicas atuantes dos professores face à participação dos encarregados de educação no processo educativo», Forum Sociológico [Online], 32 | 2018, posto online no dia 16 julho 2018, consultado o 30 março 2022. URL: http://journals.openedition.org/sociologico/1898; DOI: https://doi.org/10.4000/sociologico.1898 


\title{
A AUTORIDADE DOCENTE E OS DISCURSOS E LÓGICAS ATUANTES DOS PROFESSORES FACE À PARTICIPAÇÃO DOS ENCARREGADOS DE EDUCAÇÃO NO PROCESSO EDUCATIVO
}

\section{TEACHERS' AUTHORITY AND THE DISCOURSES AND ACTING LOGICS REGARDING THE PARTICIPATION OF PARENTS IN THE EDUCATIONAL PROCESS}

José Manuel Resende

Universidade NOVA de Lisboa, Faculdade de Ciências Sociais e Humanas, Centro Interdisciplinar de Ciências Sociais (CICS.NOVA), Portugal

Luís Gouveia

Centro Interdisciplinar de Ciências Sociais (CICS.NOVA), Faculdade de Ciências Sociais e Humanas, Universidade NOVA de Lisboa, Portugal

David Beirante

Centro Interdisciplinar de Ciências Sociais (CICS.NOVA), Faculdade de Ciências Sociais e Humanas, Universidade NOVA de Lisboa, Portugal

\begin{abstract}
Resumo
O sistema educativo português é palco de complexas evoluções nas últimas décadas, tendo na massificação e descentralização os seus grandes vetores. Como parte destas políticas de descentralização estão diretivas e orientações que enfatizam a importância de envolvimento dos pais/ Encarregados de Educação no processo educativo enquanto membros da comunidade educativa, cabendo aos professores abertura nas formas de envolvimento com estes atores. Estas orientações podem, no entanto, conflituar com subjetividades produzidas pelos professores relativamente à sua prática profissional. A partir de dados recolhidos no âmbito de uma pesquisa empírica, pretende-se neste artigo explorar os sentidos críticos evidenciados por estes profissionais de ensino relativamente à relação com os pais/Encarregados de Educação enquanto questão que se enquadra na problemática da pluralidade de entendimentos relativamente ao mandato e licença profissional.
\end{abstract}

Palavras-chave: relação pais-professores, envolvimento parental, regimes de ação

\begin{abstract}
The Portuguese educational system has been the stage of complex evolutions in the last decades, having massification and decentralization as its main vectors. As part of these decentralization policies are directives and guidelines that emphasize the importance of involving parents in the educational process as members of the educational community, with teachers having to be open to forms of involvement with these actors. These guidelines may, however, conflict with the subjectivities produced by the teachers regarding their professional practice. Based on data gathered from an empirical research, this article intends to explore the critical senses evidenced by these teaching professionals regarding the relationship with parents as an issue that falls within the problem of the plurality of understandings around professional mandate and license.
\end{abstract}

Keywords: parents-teachers relationship, parental involvement, regimes of action 
As reconfigurações na relação família-escola num contexto de massificação e descentralização do sistema educativo

O sistema educativo português é palco de profundas transformações organizacionais nas últimas décadas, marcadas nomeadamente pelos processos de descentralização e desconcentração no quadro da territorialização das políticas educativas e cujas dinâmicas extravasam o território nacional (Barroso, 2000). Estas mudanças enquadram-se numa dinâmica mais abrangente de territorialização das políticas educativas, materializada numa transferência de responsabilidades para unidades territoriais e consequente reconfiguração do papel do Estado na relação com os sistemas de ensino, no sentido de transição de um papel de avaliação de procedimentos (característico de modelos de funcionamento centralizados do Estado) para avaliação de resultados (Afonso, 2006; Maroy, 2006). Este é, contudo, um processo que não se afigura homogéneo, variando nas suas formas em função das diferentes tradições políticas e culturais entre os diferentes países (Maroy, 2005).

A massificação da escolarização pode ser apontada como o motor destas mudanças. $O$ desenvolvimento do capital humano, mas igualmente a coesão social e promoção de uma cidadania ativa são os objetivos que orientam as políticas educativas nas últimas décadas nas sociedades de capitalismo avançado (Lessard e Tardif, 2004; Vieira, 2003), servindo a descentralização o desiderato de um maior ajustamento dos conteúdos escolares à diversidade de públicos escolares, ao invés de uma oferta curricular homogénea (Derouet-Besson, 2000; Diogo, 2008).

Como parte da política de redistribuição das responsabilidades do Estado e comunidades locais no âmbito das políticas de descentralização surgem as reconfigurações na relação escola-família (Diogo, 2008). Nomeadamente, as mudanças organizacionais que ocorrem no sistema de ensino e nos estabelecimentos de ensino incluem uma evolução do ponto de vista da intervenção institucional de pais e Encarregados de Educação (EE), como parte integrante da comunidade educativa e numa lógica de corresponsabilização em torno dos processos e resultados educativos (Sá, 2004; Torres, 2011). Além do reforço da presença institucional, no quadro da emergência dos sistemas de participação parental (Stoer e Silva, 2005), este maior envolvimento concretiza-se igualmente no plano das interações que ocorrem quotidianamente entre pais/EE e professores ao longo do ano letivo (Montandon, 1987).

Não obstante estas evoluções consubstanciadas em vários diplomas e documentos - desde legislação até aos documentos reguladores dos estabelecimentos de ensino (como é o caso parti- cular dos projetos educativos, principal instrumento de autonomia das escolas, onde estão definidas as orientações em matéria de política pedagógica que pende sobre o trabalho realizado pelo conjunto do corpo docente) - uma análise à realidade para além das políticas educativas traz à luz a existência de tensões e mal-entendidos (Dubet, 1997), e que são particularmente aludidos pelos professores quando se pronunciam sobre o seu quotidiano profissional (Resende, 2010).

Privilegiando dados obtidos a partir de um projeto de investigação ${ }^{1}$, pretende-se aqui explorar a questão dos sentidos críticos enunciados pelos professores relativamente às formas de envolvimento com os pais/EE no quadro de uma pluralidade das formas atuantes no exercício da atividade docente (Resende, 2003; 2010) e entendimento do mandato e licença profissional (Abbott, 1988; Hughes, 1985).

\section{A autoridade docente e a pluralidade de lógicas atuantes na relação com os pais/Encarregados de Educação}

A questão do exercício da autoridade surge como um elemento frequentemente referido pelos professores quando se pronunciam sobre o quotidiano profissional (Barrère, 2002; Resende, 2010). A transversalidade que esta assume nos discursos críticos dos professores enquadra-se naquilo que pode ser descrito como um cenário de complexificação do exercício de autoridade por parte dos professores na relação com alunos (Lang, 2001).

Mas quando se analisa a questão do exercício da autoridade é imperioso ter desde logo em conta que, num contexto de massificação e descentralização, a realidade profissional dos professores se revela internamente segmentada (Rayou e Van Zanten, 2004), no sentido em que diferentes contextos de ensino sujeitam os professores a diferentes provas - de natureza, mas, acima de tudo, de intensidade - do ponto de vista do relacionamento com os alunos, mas também com os pais e EE.

É esta realidade heterogénea que parece sobressair do discurso de um professor ${ }^{2}$ em que compara as diferenças entre escolas periféricas (Van Zanten, $2001 ; 2004$ ) e as escolas nos centros urbanos (neste caso, no Litoral) do ponto de vista da relação de autoridade com alunos, mas também com os $\mathrm{EE}$ :

Eu estive muitos anos em escolas do Interior, e o público-alvo, os alunos do Interior, é diferente do Litoral. No Interior, as famílias por norma são mais humildes, porque respeitam mais o professor e os alunos a mesma coisa. Ou seja, a autoridade do professor, apesar de se estar a perder a olhos vistos, ano após ano, não só pelo aspeto educacional, dos alunos, mas também pela autoridade de nós 
professores por parte da tutela. Antigamente, os professores tinham mais autoridade, tinham mecanismos com os quais podiam intervir mais rapidamente. [...] Eu também trato dos processos disciplinares da escola e têm aumentado ano após ano, com comportamentos mais graves no foro disciplinar. Os pais de uma forma menos flexível, mais exigentes para com o professor, menos compreensivos; procuram uma falha que o professor possa vir a ter. $\mathrm{E}$ por isso hoje é mais difícil ser professor, com maior número de alunos, maiores problemas de ordem de relacionamento professor-alunos e professor-pais. Porque posso dizer que se calhar um determinado ato por parte de um aluno que há uns 7, 8 anos atrás era extremamente gravoso hoje passa a ser trivial. Um aluno virar as costas a um professor, um aluno mandar uma boca a um professor... Hoje em dia infelizmente isso já começa a ser o pão nosso de cada dia e antigamente isso era uma situação muito gravosa, originava logo um processo disciplinar, com consequências punitivas mais severas. (E30; docente de Educação Física; professor do Quadro; 15 anos de experiência profissional)

Sendo a experiência em diversos contextos de ensino uma marca da trajetória dos professores nos primeiros anos de carreira (Rayou e Van Zanten, 2004), no juízo que constrói a partir dos seus anos de experiência, o professor estabelece uma comparação sociogeográfica, mas também temporal, no que diz respeito às questões da autoridade. Por um lado, estabelece as diferenças do ponto de vista do "respeito" demonstrado à figura professor entre as duas regiões, e que no seu diagnóstico tem como fator decisivo as diferenças dos níveis médios de escolaridade dos pais (Diogo, 1998), que decorrem das assimetrias socioeconómicas do território português. Por outro, faz referência a uma evolução temporal, reportando-se a um "antigamente" em que a figura do professor goza de maior autoridade, e que contrasta com um contexto atual de enfraquecimento da posição deste na relação com a figura do aluno. Neste diagnóstico de fragilização que traça, parece surgir como fonte imediata as evoluções em matéria de política educativa que privam os professores de "mecanismos" institucionais para uma intervenção mais célere em situações de indisciplina e incivilidades (Gayet-Viaud, 2009; Van Zanten, 2001) por parte dos alunos.

Enquanto extensão desta fragilização da autoridade do professor, o entrevistado faz igualmente referência aos pais/EE. Descreve uma conduta que parece consubstanciar uma postura pouco colaborativa (qualificando a sua conduta como "menos flexível", de maior exigência e menor compreensão) e lógicas relacionais entendidas como de oposição ou conflituosidade para com o docente ("procuram uma falha que o professor possa ter").

Efetivamente, os discursos dos professores relativamente à indisciplina dos discentes surgem frequentemente acompanhados de outro problema que se situa a montante, nomeadamente, nas formas de relacionamento e envolvimento dos pais no trabalho educativo. Se são frequentemente apontadas pelos professores deficiências no trabalho educativo por parte dos mesmos (Barrère, 2002), as análises estendem-se igualmente a novas lógicas atuantes que marcam a relação entre professores e Encarregados de Educação, e que são frequentemente apresentadas como contendo um importante gérmen no enfraquecimento da figura da autoridade do docente na relação com os alunos (mas simultaneamente sintoma do enfraquecimento do estatuto social do professor) (Resende, 2010). Esta conjuntura contribui para aquilo que este inquirido descreve como um cenário marcado por dificuldades do ponto de vista do relacionamento "professor-alunos", mas que se estende ao binómio "professor-pais".

Com efeito, além da relação com os alunos, os juízos críticos destes profissionais focam-se igualmente nos problemas de relacionamento com os pais/EE. É o que ressalta do discurso de outro docente entrevistado:

[...] e isso nota-se muito precisamente em alunos que têm de certa forma falta de educação e formação, e muitas vezes a escola tem que impor as regras que eles não conhecem. Quando a escola impõe as regras, os alunos o que é que fazem: "O professor é assim, e é assado", telefonam para casa e os paizinhos passada meia hora estão cá na escola para saber com o professor e para saber o que se passou. "O Professor é assim, que é assado...". (E12; docente de História; professor do Quadro; 26 anos de experiência profissional)

Se o aluno assume frequentemente a posição de intermediário na comunicação entre a figura do professor e o Encarregado de Educação (Perrenoud, 2001), os problemas disciplinares em sala de aula (mas também os seus efeitos no aproveitamento escolar dos discentes) surgem nos discursos dos professores como particular elemento objeto de contestação ou tensão entre estas duas figuras (Gouveia, 2017).

É a partir desta contextualização, e com vista à obtenção de um outro olhar sobre as lógicas de ação e formas de envolvimento dos professores com os Encarregados de Educação, que uma outra técnica pode ser mobilizada. 
No quadro de uma abordagem praxeológica ${ }^{3}$, o propósito é o de aceder à multiplicidade de formas de racionalidade postas em prática pelos atores em diversos contextos, não apenas no espaço público, mas também em outros enquadramentos, como o espaço profissional (Boltanski, 2011). É o caso das operações críticas e lógicas atuantes dos profissionais de ensino relativamente à sua atividade profissional (Resende, 2003). O acesso a esta efervescência crítica pode ser feito através das diversas técnicas de análise e recolha de dados, desde a análise documental, passando pelas entrevistas e observação etnográfica. Outra técnica em particular tem sido trabalhada no âmbito de um programa de investigação mais vasto (Caetano, 2014; Dionísio, 2009; Martins, 2010; Resende, 2010), e que consiste no questionário por cenários.

Visando uma contraposição de diferentes gramáticas que orientam as perspetivas dos atores em torno de uma temática apresentada (Danic, Delalande e Rayou, 2006), a construção deste dispositivo metodológico obedece a um conjunto de princípios fundamentais. Aos inquiridos é apresentada uma narrativa que se pretende dilemática, dando azo à escolha de diferentes posicionamentos críticos e regimes de envolvimento em função da situação descrita - adotando a ação que convém (Thévenot, 1990). A construção desta narrativa tem de obedecer ao pressuposto fundamental de aparência de realidade - isto é, situações que os inquiridos reconheçam como verosímeis, remetendo-os, neste caso em particular, para a sua experiência profissional.

Esta narrativa é ainda acompanhada de um conjunto de proposições, hipóteses de saída, que exprimem diferentes posicionamentos críticos e formas de envolvimento face à situação dilemática. Além da escolha da proposição que os inquiridos consideram mais injusta, aos inquiridos é solicitada ainda a redação de uma justificação para a opção selecionada.

É a partir deste conjunto de pressupostos sucintamente descritos que, no âmbito de uma pesquisa centrada no quotidiano profissional docente, esta técnica foi aplicada a professores do sistema de ensino público português ${ }^{4}$. São aqui apresentados alguns dos resultados obtidos relativamente a um dos cenários aplicados ${ }^{5}$.

Este cenário ilustra justamente uma situação recorrente do quotidiano profissional dos professores: uma situação de contestação por parte de um Encarregado de Educação da medida disciplinar aplicada sistematicamente por uma professora a um aluno que demonstra um comportamento desajustado ao espaço da sala de aula, exercendo a medida disciplinar de expulsão da sala de aula numa interpretação estrita do regulamento. A salvaguarda do interesse coletivo, o direito à aprendizagem dos restantes alunos, constitui a base moral da professora no cenário para a opção tomada.

O objetivo é então, a partir das apreciações críticas dos inquiridos relativamente à situação descrita, o de analisar os regimes de envolvimento na ação (Boltanski e Thévenot, 2006; Thévenot, 2006), por um lado, que são mobilizados perante aquela que é uma situação de indisciplina em contexto de sala de aula, mas também, e enquanto objeto de particular atenção neste caso, a relação com os Encarregados de Educação.

A análise das justificações permite um primeiro vislumbre sobre as categorias de resposta cons-

Quadro $1 \triangleright$ Cenário 6

Numa turma do $11 .^{\circ}$ ano, uma professora de Química tem o hábito de expulsar das suas aulas um aluno em particular. Desde a primeira aula entende que este é um aluno que não respeita as regras básicas de comportamento numa sala de aula e que não tem qualquer interesse pela escola. Para não perturbar o ritmo de aprendizagem da restante turma e não atrasar o programa da disciplina, opta por colocá-lo fora da sala de aula assim que, após dar-Ihe uma primeira advertência, o aluno volta a perturbar a aula.

A meio do ano letivo, o encarregado de educação desloca-se à escola para uma reunião com a professora e a diretora de turma. O pai do aluno reclama da conduta da professora, que entende ser "demasiado severa" e que devia antes procurar acompanhar de forma mais próxima o aluno para o motivar. A docente, por sua vez, responde que não é sua obrigação ensinar o aluno a comportar-se numa sala de aula.

Das soluções expostas em baixo, indique a mais injusta e a mais justa.

A. A decisão da professora é correta e deve ser respeitada a sua autonomia nas medidas disciplinares que toma.

B. O encarregado de educação deve aceitar a conduta da professora e cooperar para melhorar a conduta do seu educando.

C. A conduta da professora é incorreta e deve procurar ser mais transigente com o aluno.

D. Mesmo discordando da conduta da professora, o encarregado de educação não deve intrometer-se na sua decisão.

E. A professora deve procurar aproximar-se do aluno de modo a compreender as razões e dessa forma procurar corrigir o seu comportamento, indo assim ao encontro das pretensões do pai.

Fonte: Gouveia (2017). 
truídas, bem como sobre as respetivas proporções entre o total de respondentes, e que traduzem a diversidade de juízos e regimes de ação que o cenário suscita ${ }^{6}$.

Num polo, parecem estar os docentes que assentam numa perspetiva de respeito do Encarregado de Educação pela decisão da professora. Entre os inquiridos, $36,7 \%$ inserem-se na categoria $A$ decisão da professora é correta/o EE deve assumir a responsabilidade/respeitar. Mostram-se alinhados com a decisão da professora, cabendo ao Encarregado de Educação colaborar, ao invés de assumir a posição crítica que assume no cenário. Esta perspetiva surge de forma ainda mais vincada entre os $7,3 \%$ dos inquiridos que entendem que $A$ professora deve ter autonomia sobre questões disciplinares em sala de aula/não deve ser questionada.

Num segundo polo, embora também com importantes nuances que diferenciam as diversas categorias, estão os inquiridos que tendem a distanciar-se da política disciplinar adotada pela professora em sala de aula.

Contrários, por um lado, à perspetiva de não assunção de posição crítica por parte do Encarregado de Educação, surgem 16,5\% dos docentes, que consideram que $O E E$ deve poder contestar $e$ colaborar na resolução do caso.

Por fim, é identificável um terceiro grupo de inquiridos. Convergindo também na perspetiva favorável à medida disciplinar da professora descrita no cenário, estão 9,2\% dos inquiridos, entendendo, contudo, que a ação disciplinar deve ser complementada por uma aproximação ao aluno ( $A$ conduta $d a$ professora é correta + deve conversar com aluno/EE), ao invés do uma ação assente apenas na aplicação da sanção disciplinar de expulsão da sala de aula?.

Uma análise mais pormenorizada das justificações permite então uma mais apurada compreensão da diversidade de juízos em confronto e as gramáticas que os fundamentam.

As justificações na categoria $A$ decisão da professora é correta/o EE deve assumir a responsabilidade/colaborar são marcadas pela posição de intransigência relativamente ao cumprimento das regras e manutenção da ordem no espaço da sala de aula por parte de um professor. A responsabilidade de promover a alteração do comportamento é, concomitantemente, transferida sobretudo para o Encarregado de Educação e para o aluno, como o excerto escolhido pretende ilustrar: "Um professor tem um papel específico: o de ensinar! A Educação passa sobretudo e fundamentalmente pelos pais. Se o aluno não sabe estar numa sala de aula, se não cumpre as regras básicas de comportamento, deve ser punido." (Q45: Escola $B$; género masculino; 30 anos de atividade; docente de Francês)

Numa retórica em que o mundo inspirado surge como suporte para o posicionamento, a instrução, o "ensinar" é entendido como a função primordial do professor. Não deixa de se vislumbrar, contudo, uma perspetiva compósita neste juízo, na medida em que a função de educar pertence não exclusivamente, mas "fundamentalmente aos pais". O mundo doméstico não é totalmente apartado por parte do inquirido no que diz respeito às funções que compõem o mandato docente, mas surge, sim, de forma particularmente matizada, sendo o polimento de condutas uma competência atribuída essencialmente ao universo familiar.

Ainda nesta categoria, outros inquiridos ancoram a sua perspetiva numa gramática cívica, no sentido de colocar o enfoque na preservação do interesse coletivo da turma. É o caso do próximo excerto.

Este é um problema grave de educação, quer dos pais quer dos filhos. Um aluno, por não saber estar numa aula, não tem o direito de prejudicar a aprendizagem dos outros alunos. O pai devia era envergonhar-se por ter um filho que revela este tipo de mau comportamento. (Q56: Escola C; género feminino; anos de atividade não especificados; docente de Português)

A tónica é colocada sobre "o direito de [...] aprendizagem dos outros alunos" como base moral para a conduta disciplinar da docente, criticando nessa medida a contestação da decisão por parte do Encarregado de Educação na justa medida em que a conduta do educando é prejudicial para a aprendizagem da restante turma.

É na categoria A professora deve ter autonomia sobre questões disciplinares em sala e aula/ não deve ser questionada que surge de forma mais vincada uma conceção autonómica do exercício da autoridade no espaço da sala de aula. Esta perspetiva ancorada no mundo inspirado é verificável no excerto que se segue.

Ao nível do ensino secundário, e com exames nacionais, o comportamento dos alunos deverá ser o mais correto para um bom ambiente de trabalho. $\mathrm{O}$ aluno que tem um comportamento incorreto não pode prejudicar os colegas e estar constantemente a perturbar o ritmo de aprendizagem dos colegas. 0 professor deverá ter autonomia para gerir a sua aula. (Q104: Escola $E$; género feminino; 30 anos de atividade; docente de Filosofia)

Na sua justificação, a arrogação para a figura do professor da "autonomia para gerir a sala de aula" assume centralidade no juízo moral construído pela inquirida. Por outro lado, a argumentação surge associada igualmente à lógica cívica de preservação 
do interesse coletivo enquanto bem comum, sendo dever do docente assegurar um "bom ambiente de trabalho", neutralizando elementos perturbadores do "ritmo de aprendizagem" dos restantes alunos da turma.

Ora, no quadro de uma ação plural e compósita por parte dos professores em função dos diferentes contextos (Resende, 2010), é justamente nesta questão que ressalta da justificação que a inquirida adota aquilo que entende ser a ação que convém, tendo em conta as particularidades da situação (Thévenot, 1990). Nomeadamente, esta associação ao mundo cívico afigura-se como a mais ajustada ao carácter específico da situação: o contexto de "ensino secundário" e a circunstância dos "exames nacionais" identificados pela inquirida afiguram-se como elementos preponderantes no juízo moral que constrói.

No caso dos inquiridos na categoria O EE deve poder contestar e colaborar na resolução do caso, é evidente uma demarcação de perspetivas que atribuem à figura do docente autonomia (total e inquestionável) nas decisões disciplinares que toma em sala de aula, numa extensão da conceção da sala de aula enquanto santuário (Dubet, 2002) onde o professor titular da turma assume o papel hegemónico nas opções tomadas. Os excertos que se seguem ilustram este ponto de vista.

As questões pedagógicas e disciplinares não devem ser tratadas num círculo fechado, circunscrito ao poder da autoridade docente; o direito à autonomia não deve excluir o sentido da responsabilidade partilhada e da cooperação (abertura ao outro), tendo em vista a resolução/superação do problema a contento de todos. (Q10: Escola $A$; género masculino; 28 anos de atividade; docente de Educação Física)

Afastando-se de interpretações exclusivamente ancoradas no mundo inspirado, o inquirido contesta formas atuantes assentes num entendimento "circunscrito ao poder da autoridade docente" ou realizadas "num círculo fechado". Ao invés, a sua perspetiva crítica assenta numa conceção híbrida, no sentido de uma composição entre o mundo inspirado e cívico: a margem de autonomia de que o professor (um "direito" que reconhece aos docentes) deve usufruir no exercício da autoridade na sala de aula não deve existir em prejuízo simultaneamente de uma "responsabilidade partilhada" e em "cooperação" com outros atores (neste caso, os pais) - condição para uma resolução do problema disciplinar em mãos de forma satisfatória para todas as partes envolvidas.

Por fim, as justificações na categoria $A$ conduta da professora é correta + deve conversar com o
aluno/EE são marcadas pela preconização de uma ação compósita perante situações de indisciplina, em que uma intervenção na sala de aula baseada num cumprimento das regras de comportamento deve ser acompanhada, no entanto, de uma ação de proximidade junto do aluno para uma efetiva resolução do problema. É o que se pretende ilustrar com o excerto que se segue.

Ainda que o Encarregado de Educação deva cooperar na educação do seu educando, o professor deverá procurar igualmente todos os meios ao seu dispor, enquanto docente, para motivar o seu aluno e não incorrer nos mesmos erros em todas as aulas.

Deve, assim, se necessário, conversar particularmente com o aluno, fazer reforços positivos, elogiando-o em pequenas situações, e não pode, sobretudo, criar uma situação de friç̧ão ou de medida de forças. (Q88: Escola D; género feminino; 19 anos de atividade; docente de Português)

Não deixando de chamar à colação as responsabilidades do Encarregado de Educação enquanto educador, e, nessa medida, de colaborar na correção do comportamento do aluno, a inquirida chama igualmente à figura do professor a responsabilidade de usar "todos os meios ao seu dispor" para intervir e procurar alterar o comportamento do aluno. No desenvolvimento, a inquirida descreve uma abordagem enquadrada num regime de ação de proximidade (Thévenot, 2006), particularista: "conversar particularmente com o aluno", utilizar "reforços positivos" no relacionamento pedagógico - ações que têm como fim fundamental "motivar" o aluno para a disciplina. Esta descrição é reveladora de uma lógica atuante no envolvimento com os alunos que pressupõe o recurso a um conjunto de táticas de adaptação contextual (van Zanten, 2004), num contexto de escolarização de massas e em que a adesão à ordem escolar e aos saberes escolares não é espontânea junto de segmentos significativos de alunos. De resto, uma abordagem que, no seu carácter tático na forma de envolvimento com a figura do aluno, evita igualmente, na ótica da inquirida, situações de "fricção" ou de "medida de forças" com o aluno que resultaria de um cumprimento escrupuloso dos regulamentos enquanto forma de envolvimento associada a regime de ação em plano (Thévenot, 2006).

\section{As lógicas de profissionalidade docente no quadro de uma escola atravessada por uma pluralidade de princípios de justiça}

A questão da relação escola-família é um tema que está significativamente presente na análise 
sociológica e analisada sob diversos ângulos - desde a relação escola-família em função das desigualdades sociais (Stoer e Silva, 2005) à relação das famílias com os processos de escolarização (Diogo, 2008; Vieira, 2003). Por outro lado, no que diz particularmente respeito à questão das relações e tensões entre professores e pais, ela é frequentemente enquadrada na problemática de uma indefinição de papéis na relação entre professores e pais/EE (Dubet, 1997; 2002; Silva, 2006).

Ora, numa escola atravessada por uma pluralidade de princípios de justiça relativamente ao seu funcionamento (Derouet, 1992), a ação dos atores afigura-se em si também plural. Mais do que uma ambiguidade, hibridismo ou fragmentação de papéis (Thollembeck, 2009), o enfoque é neste caso colocado sobre a pluralidade de lógicas atuantes adotadas, permitindo um olhar mais fino sobre as diferentes formas de envolvimento dos professores com a sua atividade - as diferentes composições na ação plural dos professores em função dos diferentes contextos e situações (Boltanski e Thévenot, 2006; Resende, 2003; 2010; Thévenot, 2006).

Num contexto de complexificação do exercício da atividade docente, motivado por mudanças sociais e organizacionais, novas formas identitárias profissionais (Dubar, 1991) têm lugar. Verifica-se uma coexistência entre diferentes lógicas atuantes no exercício da atividade (e, neste caso, nos discursos atuantes em torno da dimensão da autoridade docente na relação com os alunos e com os pais), ao invés de um modelo hegemónico de profissionalidade docente (Lessard e Tardif, 2004) ${ }^{8}$.

Efetivamente, as políticas educativas nas últimas décadas surgem orientadas para uma conversão identitária enquanto um dos pilares de uma mudança no funcionamento do sistema educativo (juntamente com as políticas de descentralização) (Maroy, 2006). Entre essas mudanças nas práticas profissionais encontra-se um entendimento da atividade do professor enquanto institucionalmente enquadrada, cabendo ao professor participar nos mecanismos e dinâmicas de interação com outros atores (Maroy, 2004; 2006). Uma das dimensões destas novas formas de profissionalidade prende-se justamente com o relacionamento com a figura do Encarregado de Educação/pais. Ao invés de serem entendidos como meros atores passivos no processo educativo, estes constituem agentes colaboradores, cabendo nessa medida também abertura ao professor (Maroy, 2004; 2006). Este desiderato de um maior envolvimento destes agentes constitui um dos pilares em matéria de política educativa nas últimas décadas (Tardif e Lessard, 2004) e tem necessariamente implicações do ponto de vista do mandato e profissionalidade daqueles que são os principais profissionais do trabalho de socialização política realizado no seio da instituição escolar (Resende, 2010).
Ora, estas mudanças preconizadas e com respaldo nas agências e instâncias internacionais (Tardif, Lessard e Gauthier, 1998) podem conflituar com a pluralidade de subjetividades e lógicas atuantes que os profissionais de ensino produzem relativamente à sua atividade, ao seu mandato profissional (Abbott, 1988; Hughes, 1985) - além de que não deixa de ser possível identificarem-se variações nestas conceções e normas profissionais segundo diferentes contextos de ensino e culturas profissionais do respetivo corpo de professores entre diferentes países (Malet e Brisard, 2005).

$\mathrm{Na}$ dimensão da atividade docente que se procura aqui abordar, alguns docentes manifestam lógicas atuantes associadas ao mundo inspirado na composição de regimes de ação que fazem na relação com os pais/EE (enfatizando a lógica estatutária e a autonomia nas decisões para o professor no espaço da sala de aula), não assentando necessariamente de forma exclusiva neste mundo (como é o caso da associação ao mundo doméstico, no sentido de reconhecimento da componente educativa nos entendimentos da atividade docente, embora manifestando reservas do ponto de vista das suas implicações sobre o estatuto social da profissão) (Resende, 2010). Outros professores não deixam de manifestar nos seus discursos atuantes composições onde têm lugar lógicas negociais na relação com alunos e pais, enquadradas num regime de ação de proximidade (Thévenot, 2006), mas também associadas ao mundo cívico (numa perspetiva de abertura à participação e envolvimento dos pais no processo educativo enquanto membros de uma mesma comunidade educativa).

Nesta pluralidade atuante, as composições construídas pelos professores são suscetíveis de assumir formas distintas em função de cada situação - uma pluralidade na ação que escapa a perspetivas analíticas que se apoiam em tipificações recíprocas de condutas.

\section{Notas}

1 Os dados apresentados neste artigo foram recolhidos no âmbito de um projeto de doutoramento financiado pela Fundação para a Ciência e a Tecnologia intitulado "Porque se mobilizam os professores? Representações colectivas e coordenações de acções públicas dos professores do Ensino Básico e Secundário em função dos juízos plurais sobre $o$ que é um bom profissional de ensino num contexto de incerteza" (SFRH/BD/80811/2011). Esta investigação tem como mote central as controvérsias em torno das alterações que decorrem da reforma do Estatuto da Carreira Docente de 2007, levadas a cabo aquando do XVII Governo Constitucional e tendo como titular da pasta da Educação Maria de Lurdes Rodrigues, sendo estas geradoras de profundas controvérsias no seio do corpo profissional docente e instigadoras de um conflito público entre este, enquadrado pelos diversos sindicatos da classe, e a equipa ministerial. Contudo, 
a pesquisa abrange igualmente outras dimensões do desempenho profissional dos professores, entre as quais a da autoridade docente. Esta dimensão abrange os juízos produzidos pelos professores, tanto em relação à figura do discente, como na relação com os pais/EE.

2 Numa descrição sucinta do protocolo metodológico, o trabalho de campo tem lugar em 5 escolas do sistema de ensino público português (que lecionam ao nível do 3. Ciclo do Ensino Básico e Secundário). Os estabelecimentos de ensino foram escolhidos tendo em conta o pressuposto metodológico de obter públicos escolares social e geograficamente contrastantes. A escola " $A$ " situa-se num município a norte de Portugal, com alunos maioritariamente filhos de pequenos agricultores e empresários com baixas qualificações escolares. A escola "B" situa-se no centro do município de Lisboa e alberga uma população estudantil socialmente diversa, registando-se uma muito significativa presença de alunos de famílias carenciadas e beneficiárias de Apoio Social Escolar. A escola " $C$ " situa-se num município adjacente ao município de Lisboa e apresenta uma população estudantil onde predominam alunos oriundos de classe média. A escola "D", localizada no centro de Lisboa, conta com uma população escolar composta por significativos contingentes de alunos oriundos da classe média alta, registando-se em maior percentagem os pais/EE com habilitações superiores. Por fim, a escola "E", situada num município do Interior-Sul de Portugal, apresenta um perfil de alunos maioritariamente oriundos de classes populares.

No caso das entrevistas semidiretivas, foram, ao todo, realizadas 40 entrevistas. Através de uma amostragem aleatória por quotas, em cada uma das 5 escolas 8 entrevistas são realizadas - duas por cada agrupamento de disciplinas (Línguas, Ciências Sociais, Ciências Experimentais e Expressões).

3 No quadro da abordagem teórica comummente designada por Sociologia Pragmática ou Praxeológica, a ação é entendida a partir das modalidades através das quais os atores se envolvem na ação, nas formas de coordenação com os outros e consigo mesmos. Estas diferentes modalidades de envolvimento constituem diferentes regimes de envolvimento na ação, sendo cada regime convocado em função do juízo realizado pelo ator em cada situação. Três regimes de envolvimento na ação podem ser distinguidos: o regime de ação familiar (caracterizado por uma dinâmica de envolvimento particularista e personalizada); regime de envolvimento em plano (modo de envolvimento com um ambiente funcionalmente preparado para a execução de um plano orientado para atingir objetivos estabelecidos); e regime de justificação pública (em que a ação é orientada por convenções de grande alcance) (Thévenot, 2006). É através deste complexo corpo teórico-conceptual que se pretende justamente compreender em que diferentes regimes de envolvimento na ação os professores assentam as suas práticas e lógicas discursivas e que exprimem a pluralidade de juízos em torno do que é um bom profissional de ensino (Resende, 2003; 2010).

4 O inquérito aplicado é composto ao todo por 8 cenários, construídos e distribuídos por 4 eixos de análise definidos para a pesquisa. A amostra é constituída a partir dos dados estatísticos recolhidos de cada uma das 5 escolas (ver nota 2), e considerando as variáveis género, área disciplinar, vínculo profissional e área disciplinar. Ao todo, 112 questionários foram validados.
5 A narrativa apresentada integra um questionário mais extenso composto por um total de 8 cenários. Estes estão organizados em 4 eixos analíticos, entre os quais um relativo à autoridade docente (Gouveia, 2017). A escolha do presente cenário deve-se ao facto de ser delineado com o intuito de abordar justamente a questão da autoridade docente na relação com os pais/EE. As conceções aventadas pelos professores são construídas (através da narrativa que incorpora uma situação de intervenção de um EE numa decisão disciplinar) a partir da questão dos moldes em que a intervenção dos pais deve ser feita. Os juízos críticos e lógicas atuantes expressos por estes profissionais surgem, nesta medida, enquadrados nas suas conceções sobre as formas de envolvimento dos docentes com os pais enquanto agentes do processo educativo (e em particular num contexto de diretivas políticas orientadas para um maior envolvimento destes no respetivo estabelecimento de ensino na qualidade de membros de uma mesma comunidade educativa).

6 Devido às limitações de espaço, a descrição dos resultados das proposições não é apresentada neste artigo, privilegiando-se a análise das justificações de alguns dos inquiridos.

7 Neste último grupo identificado, ficam fora de uma análise mais detalhada as categorias $A$ professora deve aproximar-se do aluno (7,3\%) e $A$ conduta da professora é incorreta; deve mudar de estratégia (8,3\%).

8 Se a profissionalização diz respeito à melhoria do estatuto profissional, o conceito de profissionalidade é relativo ao conjunto de saberes, competências, atitudes e valores que compõem a atividade do professor (Nóvoa, 1992).

\section{Referências bibliográficas}

Abbott, A. (1988). The system of professions. An essay on the division of expert labour. Chicago: The University of Chicago Press.

Afonso, N. (2006). A Direção Regional de Educação: Um espaço de regulação intermédia. In J. Barroso (Org.), A regulação das políticas públicas de educação (pp. 71-97). Lisboa: Educa.

Barrère, A. (2002). Les enseignants au travail. Routines incertaines. Paris: L'Harmattan.

Barroso, J. (2000). Autonomie et modes de régulation locale dans le système éducatif. Revue française de pédagogie, (130), 57-71.

Boltanski, L. (2011). On critique. A sociology of emancipation. Cambridge: Polity.

Boltanski, L., \& Thévenot, L. (2006 [2001]). On justification. Economies of worth. Princeton: Princeton University Press.

Caetano, P. (2014). Individuação e reconhecimento: Processos de socialização política na incerteza dos itinerários escolares (Tese de doutoramento). Universidade Nova de Lisboa, Faculdade de Ciências Sociais e Humanas, Lisboa, Portugal.

Danic, I., Delalande, J., \& Rayou, P. (2006). Enquêtes auprès d'enfants et de jeunes: Objets, méthodes et terrains de recherche en sciences sociales. Rennes: PU Rennes. 
Derouet, J.-L. (1992). École et justice. De l'égalité des chances aux compromis locaux. Paris: Éditions Métailié.

Derouet-Besson, M.-C. (2000). L'évolution des politiques publiques de constructions scolaires depuis trente ans: Diversification des sources de légitimité et changement des lieux de décision. In J.-L. Derouet (Ed.), L'école dans plusieurs mondes (pp. 3-36). Bruxelles: De Boeck Université.

Diogo, A. M. (1998). Famílias e escolaridade: Representações parentais da escolaridade, classe social e dinâmica familiar. Lisboa: Colibri.

Diogo, A. M. (2008). Investimento das famílias na escola. Dinâmicas familiares e contexto escolar local. Lisboa: Celta.

Dionísio, B. (2009). A orientação no plural. Promessas e limites do serviço público de orientação escolar (Tese de doutoramento). Universidade Nova de Lisboa, Faculdade de Ciências Sociais e Humanas, Lisboa, Portugal.

Dubar, C. (1991). La socialisation: Construction des identités sociales et professionnelles. Paris: Armand Colin.

Dubet, F. (Ed.) (1997). École, familles: Le malentendu. Paris: Textuel.

Dubet, F. (2002). Le déclin de l'institution. Paris: Seuil.

Gayet-Viaud, C. (2009). La politesse dans la relation pédagogique. Éléments de réflexion sur le réglage de la distance entre maîtres et élèves. In V. Deshoulières, \& M. Constantinescu (Eds.), Les funambules de l'affection. Maîtres et disciples (pp. 113-133). Clermont-Ferrand: Presses Universitaires Blaise Pascal.

Gouveia, L. (2017). Porque se mobilizam os professores? Representações colectivas e coordenações de acções públicas dos professores do ensino básico e secundário em função de juízos plurais sobre o que é ser um bom professor em contexto de incerteza (Tese de doutoramento). Universidade Nova de Lisboa, Faculdade de Ciências Sociais e Humanas, Lisboa, Portugal.

Hughes, E. C. (1985). The sociological eye: Selected papers. New Brunswick: Transaction Publishers.

Lang, V. (2001). La profession enseignant en France: Permanence et éclatement. Éducation et Francophonie, 29(1), 52-69.

Lessard, C., \& Tardif, M. (2004). Les transformations actuelles de l'enseignement: Trois scénarios possibles dans l'évolution de la profession enseignante?. In M. Tardif, \& C. Lessard (Eds.), La profession d'enseignants aujourd'hui. Évolutions, perspectives et enjeux internationaux (pp. 265-287). Bruxelles: De Boeck Université.

Malet, R., \& Brisard, E. (2005). Travailler ensemble dans l'enseignement secondaire en France et en Angleterre. Recherche et Formation, (49), 17-33.

Maroy, C. (2004). Le modèle du praticien réflexif à l'épreuve de l'enquête en Belgique. In M. Tardif, \& C. Lessard (Eds.), La profession d'enseignants aujourd'hui. Évolutions, perspectives et enjeux internationaux (pp. 67-93). Bruxelles: De Boeck Université.

Maroy, C. (2005). Une comparaison des formes de régulation intermédiare dans cinq pays européens. In Y. Dutecq (Org.), Les régulations des politiques d'éducation (pp. 51-84). Rennes: Presses Universitaires de Rennes.

Maroy, C. (2006). Les évolutions du travail enseignant en France et en Europe: Facteurs de changement, incidences et résistances dans l'enseignement secondaire. Revue française de pédagogie, (155), 111-142.

Martins, A. C. (2010). A medicina paliativa como medicina de proximidade. Suspensão dos julgamentos gerais e acção médica em regime de familiaridade (Tese de doutoramento). Universidade Nova de Lisboa, Faculdade de Ciências Sociais e Humanas, Lisboa, Portugal.

Montandon, C. (1987). L'essor des relations famille-école. Problèmes et perspectives. In P. Perrenoud, \& C. Montadon (Orgs.), Entre parents et enseignants: Un dialogue impossible? (pp. 23-47). Paris: Peter Lang.

Nóvoa, A. (1992). Formação de professores e profissão docente. In A. Nóvoa (Org.), Os professores e a sua formação (pp. 13-33). Lisboa: Publicações D. Quixote.

Perrenoud, P. (2001). Entre a família e a escola, a criança mensageira e mensagem. O go-between. In C. Montandon, \& P. Perrenoud (Eds.), Entre pais e professores: Um diálogo impossível? Para uma análise sociológica das interações entre a família e a escola (pp. 29-56). Oeiras: Celta.

Rayou, P., \& Van Zanten, A. (2004). Enquête sur les nouveaux enseignants. Changeront-ils l'école?. Paris: Bayard.

Resende, J. M. (2003). O engrandecimento de uma profissão: Os professores do ensino secundário público no Estado Novo. Lisboa: FCT/Fundação Calouste Gulbenkian.

Resende, J. M. (2010). A sociedade contra a escola? A socialização política escolar num contexto de incerteza. Lisboa: Instituto Piaget.

Sá, V. (2004). A participação dos pais na escola pública portuguesa. Uma abordagem sociológica e organizacional. Braga: Instituto de Educação e Psicologia/ Universidade do Minho.

Silva, P. (2006). Pais-professores: Reflexões em torno de um estranho objecto de estudo. Interacções, (2), 268-290.

Stoer, S., \& Silva, P. (Orgs.) (2005). Escola-família, uma relação em processo de reconfiguração. Porto: Porto Editora.

Tardif, M., \& Lessard, C. (2004). Introduction. In M. Tardif, \& C. Lessard (Eds.), La profession d'enseignants aujourd'hui. Évolutions, perspectives et enjeux internationaux (pp. 1-17). Bruxelles: De Boeck Université.

Tardif, M., Lessard, C., \& Gauthier, C. (1998). Introduction générale. In M. Tardif, \& C. Lessard (Eds.), Formation des maîtres et contextes sociaux (pp. 7-70). Paris: PUF. 
Thévenot, L. (1990). L'action qui convient. In P. Pharo, \& L. Quéré (Eds.), Les formes de l'action. Sémantique et sociologie (pp. 39-69). Paris: Éditions de I'EHESS.

Thévenot, L. (2006). L'action au pluriel: Sociologie des régimes d'engagement. Paris: Éditions La Découvert.

Thollembeck, J. (2009). Malentendus dans les relations familles-école: La question des origines. Analyse, (20), 1-9.

Torres, L. L. (2011). A construção da autonomia num contexto de dependências. Limitações e possibilidades nos processos de (in)decisão na escolar pública. Educação, Sociedade e Culturas, (32), 91-109.
Van Zanten, A. (2001). L'école de la périphérie. Scolarité et ségrégation en banlieue. Paris: PUF.

Van Zanten, A. (2004). L'influence des normes d'établissement dans la socialisation professionnelle des enseignants: Le cas des professeurs des collèges périphériques français. In $\mathrm{M}$. Tardif, \& C. Lessard (Eds.), La profession d'enseignants aujourd'hui. Évolutions, perspectives et enjeux internationaux (pp. 207-223). Bruxelles: De Boeck Université.

Vieira, M. M. (2003). Famílias e escola: Processos de construção da democratização escolar. In M. M. Vieira, J. Pintassilgo, \& B. P. Melo (Orgs.), Democratização escolar: Intenções e apropriações (pp. 75-103). Lisboa: Centro de Investigação em Educação-FC/UL.

Recebido a 31/08/2017. Aceite para publicação a 13/12/2017.

José Manuel Resende (josemenator@gmail.com). Universidade NOVA de Lisboa, Faculdade de Ciências Sociais e Humanas, Centro Interdisciplinar de Ciências Sociais (CICS.NOVA), Portugal; Observatório Português da Juventude, Portugal; Universidade Estadual do Norte Fluminense Darcy Ribeiro, Programa de Pós-Graduação em Sociologia Política, Brasil; Universidade Federal Fluminense, Instituto Nacional de Estudos Comparados em Administração de Conflitos (INCT-InEAC) \& Laboratório de Etnografia Metropolitana (LeMetro), Brasil. CICS.NOVA, Edifício I\&D, Avenida de Berna, 2, 1069-061 Lisboa, Portugal.

Luís Gouveia (Icgouveia86@gmail.com). Centro Interdisciplinar de Ciências Sociais (CICS.NOVA), Faculdade de Ciências Sociais e Humanas, Universidade NOVA de Lisboa. Edifício I\&D, Avenida de Berna, 2, 1069-061 Lisboa, Portugal.

David Beirante (dbeirante@gmail.com). Centro Interdisciplinar de Ciências Sociais (CICS.NOVA), Faculdade de Ciências Sociais e Humanas, Universidade NOVA de Lisboa. Edifício I\&D, Avenida de Berna, 2, 1069-061 Lisboa, Portugal. 